\title{
Phonetics and Phonology Paradox in Levantine Arabic: An Analytical Evaluation of Arabic Geminates’ Hypocrisy
}

\author{
Ahmad Mahmoud Saidat \\ Department of English Language and Literature, Al-Hussein Bin Talal University, Jordan \\ Jamal A. Khlifat \\ Department of Linguistics, University of Colorado, Boulder, USA
}

\begin{abstract}
This paper explores the phonetic and phonological paradox between two categories of LevantineArabic long consonants-known as geminates by looking closely at the hypocrite Arabic geminates. Hypocrite geminates are phonetically long segments in a sequence that are not contrastive. The paper seeks to demonstrate that Arabic geminates can be classified into two categories- true vs. fake geminates-based on the phonological process of inseparability and the Obligatory Contour Principle (OCP). Thirty Levantine Arabic speakers have taken part in this case study. Fifteen participants were asked to utter a group of stimuli where the two types of geminates interact with the surrounding phonological environment. The other fifteen participants were recorded while reading target word lists that contained geminate consonants and medial singleton preceded by short and long consonants and engaging in naturalistic conversations. Auditory and acoustic analyses of long consonants were made. Results from the word lists indicated that while Arabic true geminates embrace the phonological process of inseparability, Arabic fake geminates do not. The case study also shows that the OCP seems to bridge the contradiction between these two categories of Arabic geminates.
\end{abstract}

Index Terms -Arabic geminates, epenthesis, inseparability, obligatory contour principle, CV phonology

\section{INTRODUCTION}

Gemination refers to a phenomenon in which two identical sounds co-occur at word boundaries or in one word. Germination is a term that has been defined differently by various scholars. According to Crystal (2011), germination is a term used in phonology and phonetics for a sequence of identical adjacent segments of a sound in as single morpheme. Mahendra et al. (2014, p. 1) define germination as "the attempt of the single tooth bud to divide with the resultant information of the tooth with a bifid crown and usually a common root and root canal".

Gemination and assimilation have received a significant attention in Levantine Arabic. According to Ladefoged and Maddieson (1996), geminates as reported in various languages globally have been the critical source of debate regarding their phonological representation, phonetic implementation and the way to account for their specific behavior. A geminate within CV phonology is represented as a single melodic unit associated with two prosodic positions (Ball \& Rahilly, 1999). Such representations which critically relies on the theory that syllabicity is embodied on a different tier from the melodic one has also received geminate consonant analysis including post-lexical geminates.

Previous research on gemination has focused mainly on word-medial gemination, rather than word-initial and wordfinal gemination, simply because word-medial gemination is more common (Thurgood, 1993). Geminates are usually found between two vowels, although some languages do allow word-initial geminates, followed by a vowel, and wordfinal geminates, preceded by a vowel (Davis, 2011). The rarest type of gemination occurs with geminates surrounded by consonants (Davis, 2011). Phonological analysis has focused on how geminates are represented phonologically and how they can be distinguished from their singleton counterparts. Singletons are consonants surrounded by silence, diphthongs or vowels. This discussion has mainly revolved around autosegmental tiers and the linking of geminates to various representations in these tiers, which represent different kinds of syllable structure (Davis, 2011).

Our argument here grounds itself on Kenstowicz and Pyle's (1973) argument of the notion of inseparability. We have adopted this notion here to reinforce the hypotheses listed below and to bridge the gap between those conflicting points of views of geminate representation in the light of CV phonology and the Obligatory Contour Principle. Kenstowicz and Pyle (1973) contend that there seems to be two fundamental and exotic characteristics of geminate sounds; one of which is that these sounds tend to resist vowel epenthesis, known as anaptyxis (Arvaniti \& Tserdanelis, 2000). Their argument here advocates for the notion that geminate sounds compose some sort of tiers within the long sound itself, and breaking this union through an alien vowel seems resistible by the nature of these sounds per se. This actually brings us the contention of the representation of geminates, particularly in Levantine Arabic. In other words, should these sounds be represented with the feature [+ long], or should they be represented as a cluster of two sounds whose internal fundamental segments are represented as a cluster of [- long] [-long]. Clusters are two or more 
juxtaposed/contiguous consonants in the same syllable.

We also adopt Kiefer \& Sterkenburg's (2012) assumption of inseparability of phonology that all phonetic processes essentially depend on morphological and syntactic structure (Kiefer \& Sterkenburg, 2012, p. 970). By adopting this assumption, we respect the autonomy of phonology. Syntax and morphology play a critical role in specifying the character and range of certain sound changes.

In this regard, we have adopted the notion of inseparability to bridge the gap between such contentious views in Levantine Arabic geminates and to help us test the hypotheses listed below:

1. Arabic seems to have two kinds of long sounds/consonants (true geminates and fake geminates). While these sounds are articulatorily and orthographically perceived the same, they behave phonologically in a completely different manner. Arabic orthographies are the spelling and writing system of Arabic language. While auditory phonetics, as well as the orthographic form of the word, does not help Levantine Arabic speakers see through the actual identity of the geminate sound, Arabic phonology rules and Arabic phonology-morphology interaction provide the clues to those speakers to discern this difference between these two sub-categories of Arabic geminates.

2. While true Arabic geminates respect the notion of inseparability (integrity of the quality of the sound that cannot be negotiated and/or manipulated with epenthesis), fake Arabic geminates do not respect that in the sense that they are vulnerable to anaptyctic vowels.

3. When epenthesis transpires, the lexical meaning is maintained in fake-geminate Arabic words e whilst this meaning is completely lost in true-geminate Arabic words.

4. In the light of the Obligatory Contour Principle, fake Levantine Arabic geminates tend to be represented as a cluster of [-long] [-long] while their true counterparts tend to be represented as a unit of sound that has the feature [+long].

\section{REVIEW OF THE LITERATURE}

One of the first studies investigating the gemination in Levantine Arabic is Obrecht (1965), which investigates the perception of gemination in Arabic. Obrecht (1965) focused on the contrasts between /b/ and /bb/ (in /"xabar/ "news" and /'xabbar/ "he informed") (32); between /n/ and /nn/ (in /'bana/ "he built" and /'banna/ "mason") (34); and between /ṣ/ and /șș/ (in /'șabij/ "boy" and /'ș̣abij/ "the boy") (37). Obrecht (1965) manipulated the stop closure duration of each consonant with the pattern playback synthesizer, creating multiple versions of each consonant ranging in $20 \mathrm{~ms}$ intervals, which he then presented to native Arabic speakers in a forced choice task. Participants were primarily from the Levant who listened to the sibilant contrast. Obrecht (1965) found that the crossover point in identification differed between the different phonemes; the crossover points for the /b/-/bb/ and /ș//ș̣ / contrasts occurred in the 140-160 ms range, while that for $/ \mathrm{n} /-\mathrm{nn} /$ occurred around $90-110 \mathrm{~ms}$, which suggests that there is a duration distinction between obstruent and sonorant geminates, obstruent geminates perhaps being longer because of the greater difficulty in identifying them (39). Overall, Obrecht's (1965) study demonstrated that stop closure duration is a robust acoustic correlate of gemination that listeners can easily attend to, as perception of singleton-geminate contrasts was categorical, replicating earlier results from studies with stop closure duration by Lisker (1958) and Pickett \& Decker (1960), Obrecht (1965), Lahiri \& Hankamer (1988).

A few years later, Delattre (1971) investigated "the meaningful perceptual doubling of a consonant phoneme," mainly across word boundaries, but also within them (his main example of the latter being /rr/ in French and Spanish) (31). Such a notion of gemination does not fit the accepted definition of gemination (as at the beginning of this section), but the phenomenon of gemination due to proximity is closely related to the issue of "fake" geminates that we are detailing in this paper. (None of these languages, in fact, is generally held to contain a singleton-geminate distinction). Delattre (1971)'s study is large, looking at English, German, Spanish, and French /n/, /l/, and /s/ and including radiographic measurements of articulatory movements; the acoustic characteristics he measured included 1) singleton and geminate consonant duration; 2) overall intensity (loudness) of singletons and geminates; and 3) the duration of the vowel preceding both singleton and geminate consonants. In English, "geminate" consonants are 1.4 times longer than singleton consonants, while German "geminate" consonants are 1.5 times longer than singletons (Delattre, 1971, p. 34). Spanish and French geminates are 1.8 and 1.9 times longer, respectively, than singleton consonants (Delattre, 1971, p. 36). These duration measures are comparable to those found by Ladefoged \& Maddieson (1996), who reported, in their study of geminates from languages around the world, that "true" geminates are 1.5-3 times longer than singleton consonants in careful speech (92). Intensity measurements indicated that there was a difference in loudness between singleton and geminate consonants, $/ \mathrm{nn} /$ being somewhat lower in intensity compared to $/ \mathrm{n} /$, while $/ 1 \mathrm{l} /$ and $/ \mathrm{ss} / \mathrm{had}$ greater intensity (Delattre, 1971). The vowels preceding geminates were not appreciably different from the vowels preceding singleton consonants; there were no length distinctions (Delattre, 1971). Delattre's (1971) study is important because it first demonstrated that there is a length distinction between singleton and "fake" geminate consonants.

Lahiri \& Hankamer (1988) provide additional evidence for the importance of stop closure duration in identifying geminate consonants and, crucially, they demonstrate that there is no acoustic difference between geminates that occur tautomorphemically or by concatenation or total assimilation. So-called "fake" geminates, then, are acoustically identical to "true" geminates. Lahiri \& Hankamer (1988) investigated acoustic differences between Turkish "true" 
geminate voiceless stops $/ \mathrm{t} /$ and $/ \mathrm{tt} /$ and $/ \mathrm{k} /$ and $/ \mathrm{kk} /$ in order to determine the acoustic correlates of gemination, measuring 1) the duration of the preceding vowel, which Maddieson (1985) claims may be shorter before geminates than before singleton consonants; 2) the stop closure duration; and 3) the voice onset time (VOT) from the consonant burst to the beginning of a following vowel. Garcia-Sierra, Diehl, \& Champlin define VOT as "the time interval between the release of the articulatory occlusion and the onset of vocal-fold vibration" (Garcia-Sierra, Diehl, \& Champlin, 2009, p. 370). Results showed that vowel length was essentially identical before singleton and geminate consonants but stop closure duration proved to be a readily identifiable cue for gemination: Geminate consonants were, on average, 2.9 times longer than singleton consonants (Lahiri \& Hankamer, 1988). These results were repeated with perception; Lahiri \& Hankamer (1988) cross-spliced geminate stop closures onto singleton consonants, and Turkish listeners identified these $96 \%$ of the time as geminates (333). VOT was significant, overall, but cross-splicing stimuli with the opposite VOTs did not change identification of singletons versus geminate consonants. The average VOT difference was around $11 \mathrm{~ms}$, so, while VOT did contribute to the identification of a stop as a singleton or geminate consonant, stop closure duration was the better acoustic cue (Lahiri \& Hankamer, 1988, p. 331).

In order to investigate whether different acoustics were associated with geminates with different origins (whether they were tautomorphemic, heteromorphemic, or the result of assimilation), Lahiri \& Hankamer (1988) recorded Bengali speakers pronouncing each of the three kinds of geminates, which exist plentifully in Bengali, and nongeminates. Like with the Turkish data, they found a significant difference between singleton /t, k/ and geminate /tt, kk/ stop closure durations, finding that Bengali geminates were roughly twice as long as singleton consonants (Lahiri \& Hankamer, 1988). Differences in preceding vowel length were significant overall for singleton versus geminate consonants, but not for all speakers, as was the case with VOT in Turkish; VOT was not significant in Bengali (Lahiri \& Hankamer, 1988). Importantly, there were no acoustic differences between geminates of different types, demonstrating that, despite their phonological origins, different types of geminates are acoustically identical (Lahiri \& Hankamer 1988).

All of the previous studies have referred to word-medial gemination, whether "true" gemination or "fake" gemination, with the exception of Obrecht (1965), who included the word-initial geminate/șs/. The first experimental study investigating word-final gemination in Arabic is Al-Tamimi, Abu-Abbas, \& Tarawnah (2010), which investigated word-final gemination in Urban Jordanian Arabic using spectrographic and videofluoroscopic evidence. They note that previous non-experimental research on word-final gemination in Arabic has been conflicting, with some linguists, such as El Saaran (1951) and Mitchell (1990), arguing for word-final distinctiveness, and other linguists, such as Ghalib (1984), arguing that gemination is non-distinctive word-finally (Al-Tamimi et al., 2010).

Al-Tamimi et al. (2010) recorded eighteen Levantine Arabic speakers from the city of Irbid saying the words /sad/ "water dam," /sadd/ "closed," /man/ "who," /mann/ "did someone a favor," /lam/ "never," and /lamm/ "collected" three times in a carrier sentence, / I $\hbar k$.... $\hbar k \mathrm{k} /$ "say..., say..." (p. 115). Two separate judgment groups determined the familiarity of the words in the word list and the naturalness of the elicitations (Al-Tamimi et al., 2010). Al-Tamimi et al. (2010) measured preceding vowel duration and stop closure duration for the oral stops /d/ and /dd/ and preceding vowel duration and nasal murmur for the nasal stops $/ \mathrm{n} /, / \mathrm{nn} /, / \mathrm{m} /$, and $/ \mathrm{mm} /$. They found that vowels preceding singleton consonants were 1.4 times longer than vowels preceding geminates and that geminate consonants were 1.5 times longer than singleton consonants (Al-Tamimi et al., 2010). Videofluoroscopic evidence showed differences in muscular tension, with geminates being "produced with wider laryngo- and oropharynx, more elevated hyoid bone, narrower vertical distance between the uppermost point of tongue body and the roof of the mouth, more raised soft palate, and tighter and larger contact extents in comparison to the singleton consonants" (Al-Tamimi et al., 2010, p. 118). AlTamimi et al. (2010) theorize that a "temporal compensation" relationship exists between the shortened preceding vowel and the following longer stop closure duration of geminate consonants (121). The greater cue to gemination is the longer stop closure duration, but the shorter preceding vowel also contributes to the perception of a geminate by emphasizing the greater length of the stop closure duration.

Finally, Oh \& Redford (2012) investigated acoustic distinctions between "true" and "fake" geminates in English, noting that conflicting results have been found for "fake" geminates. They point out that Lahiri \& Hankamer (1988) did not find preceding vowel length differences between "true" and "fake" geminate consonants or between different types of "fake" geminate consonants in Bengali, whereas Ridouane (2010) did find preceding vowel length distinctions between "true" and "fake" geminates in Tashelhiyt Berber, with shorter preceding vowels before "true" geminates (Oh \& Redford, 2012). An important difference between the two studies is that Lahiri \& Hankamer (1988) investigated word-internal "fake" geminates caused by suffixation, while Ridouane (2010) investigated "fake" geminates formed from proximity across word boundaries (the same kind of gemination that Delattre (1971) investigated for English, German, Spanish, and French) (Oh \& Redford, 2012). Oh \& Redford (2012) theorize that the consonant to preceding vowel (C:V1) ratio would distinguish between "true" and "fake" geminates in Ridouane's (2010) findings. They also argue that word-boundary strengthening effects could cause a difference in the C:V1 ratio between "fake" geminates occurring across word boundaries, where "boundary-adjacent syllable lengthening" would occur, and word-internal "fake" geminates (Oh \& Redford 2012, p. 83).

Oh \& Redford (2012) also suggest that there may be differences within the category of word-internal "fake" geminates depending on how decomposable the word is. Based on findings which support dual-route models of 
processing, they argue that words may be processed holistically or decomposed into their basic parts (Oh \& Redford, 2012). What this means for word-internal "fake" geminates is that those "fake" geminates which occur in words which are highly decomposable should pattern with "fake" geminates which occur across word boundaries, while those in words which are not as highly decomposable and should be represented as single consonants (rather than two) (Oh \& Redford, 2012).

As the previous review of the acoustics literature on geminates suggests, both the type of gemination and the place of a geminate within the word may have different acoustic effects. Levantine Arabic "fake" geminates with /- $t$ / are wordinternal and concatenated, so they may pattern either with other word-internal "fake" geminates (such as assimilated geminates, like / $\mathrm{Pa} \int \mathrm{ams}$ / "the sun") and "true" geminates or with word-boundary geminates. There may or may not be vowel length distinctions before word-internal "fake" geminates, although the literature generally suggests that there will not be.

\section{METHODOLOGY}

\section{A. Participants}

Thirty native speakers of Levantine Arabic have taken part in this experiment as judges of the epenthesized words that have been uttered by a native speaker of Jordanian Arabic. Twenty-seven subjects speak Jordanian Arabic. Two subjects speak Syrian Arabic, and one subject speaks Palestinian Arabic. Out of the thirty subjects, four are women. The participants' ages have ranged between eighteen and thirty years.

\section{B. Procedure}

The native speaker of Jordanian Arabic has uttered the list of words in Table 4 below. These participants were also audio recorded in a silent room while uttering the word list of long consonants in disyllables with medial VVCCV, VCCV, VVCV, and VCV structure. We digitally made the recordings at a $44.0 \mathrm{KHz} 32$-bit sampling rate using a Sony microphone voice recorder.

However, we faced a challenge designing near-minimal sets for the four types of syllables because of the low frequency of manifestation of target words with medial VVCCV structure. The subjects rejected certain words with this medial VVCCV structure thus, yielding a fewer tokens compare to other structures. The vowel after V2 and before V1 the target consonant in each case was /aa/ or /a/, although these were sometimes recognized differently by the speakers due to Imāla. All the Levantine long consonants were elicited in their geminate and singleton form; however, this paper results for liquids, nasals and stops: $/ \mathrm{r}, \mathrm{l}, \mathrm{n}, \mathrm{m}, \mathrm{k}, \mathrm{d}, \mathrm{t}, \mathrm{b} /$. To obtain spontaneous speech, we asked the respondents to recall at least two incidents that brought saddest and happiest moments in their lives. Each of their stories lasted about four minutes.

Except for medial VV1CCV2 structure, we extracted 3 tokens per subject for each of the target long consonants in each syllable type from the wordlists for acoustic and auditory analysis. Durational measurement of V1 in milliseconds (ms), the medial CC or C target and V2 were designed using Praat Manual. Measurement of medial stops involved the closure duration, voice onset time and release burst with not attempt to separate in this case because the primary goal was to assess the overall consonant durations over different types of articulation and to compare them with the durations of the following and preceding vowels.

Table 4: Target words for each of the consonants and syllable types examined. We did not find tokens of /t/ with the medial structure VV1CCV2. 


\begin{tabular}{|c|c|c|c|c|}
\hline & $\mathrm{V} 1 \mathrm{CV} 2$ & V1CCV2 & VV1CV2 & VV1CCV2 \\
\hline $\mathrm{r}$ & $\begin{array}{l}\text { baram } \\
\text { barad } \\
\text { harab }\end{array}$ & $\begin{array}{l}\text { barram } \\
\text { barrad } \\
\text { harrab }\end{array}$ & $\begin{array}{l}\text { baarim } \\
\text { beerid } \\
\text { heerib }\end{array}$ & $\begin{array}{l}\text { maarra } \\
\text { zeerra }\end{array}$ \\
\hline 1 & $\begin{array}{l}\text { Salam } \\
\text { malak } \\
\text { Palab }\end{array}$ & $\begin{array}{l}\text { Sallam } \\
\text { mallak } \\
\text { Pallab }\end{array}$ & $\begin{array}{l}\text { Saalam } \\
\text { maalik } \\
\text { Paalib }\end{array}$ & $\begin{array}{l}\text { Paalle } \\
\text { meelle } \\
\text { feelle }\end{array}$ \\
\hline $\mathrm{n}$ & \begin{tabular}{|l|} 
bana s'anas \\
Pana؟
\end{tabular} & $\begin{array}{l}\text { banna } \\
\text { s`anna؟ } \\
\text { Panna؟ }\end{array}$ & $\begin{array}{l}\text { beene } \\
\text { s } \text { 'aaniৎ } \\
\text { Paaniৎ }\end{array}$ & $\begin{array}{l}\text { meenne } \\
\text { haanne }\end{array}$ \\
\hline $\mathrm{m}$ & $\begin{array}{l}\text { Samal } \\
\text { samą } \\
\text { hamal }\end{array}$ & $\begin{array}{l}\text { Sammal } \\
\text { sammas } \\
\text { hammal }\end{array}$ & $\begin{array}{l}\text { Saamil } \\
\text { seemah } \\
\text { haamil }\end{array}$ & $\begin{array}{l}\text { Saamme } \\
\text { seemme } \\
\text { d'aamme }^{\complement} \text { aamm }\end{array}$ \\
\hline $\mathrm{k}$ & $\begin{array}{l}\text { hakam } \\
\text { sakat sakan }\end{array}$ & $\begin{array}{l}\text { hakkam } \\
\text { sakkat } \\
\text { sakkan }\end{array}$ & $\begin{array}{l}\text { haakam } \\
\text { seekit } \\
\text { seekin }\end{array}$ & $\begin{array}{l}\text { haakke } \\
\text { seekke }\end{array}$ \\
\hline $\mathrm{d}$ & $\begin{array}{l}\text { Sadad } \\
\text { badal } \\
\text { zadal }\end{array}$ & $\begin{array}{l}\text { Saddad } \\
\text { baddal } \\
\text { 3addal }\end{array}$ & $\begin{array}{l}\text { Saadid } \\
\text { beedal } \\
\text { zeedal }\end{array}$ & $\begin{array}{l}\text { Saadde } \\
\text { 5eeded } \\
\text { zeedde }\end{array}$ \\
\hline $\mathrm{t}$ & $\begin{array}{l}\text { katab } \\
\text { Patal fatal }\end{array}$ & $\begin{array}{l}\text { kattab } \\
\text { Pattal } \\
\text { fattal }\end{array}$ & $\begin{array}{l}\text { keetib } \\
\text { Paatil } \\
\text { feetil }\end{array}$ & \\
\hline b & $\begin{array}{l}\text { Pabad } \\
\text { saba? } \\
\text { Pabad` }\end{array}$ & $\begin{array}{l}\text { Pabbad } \\
\text { sabba? } \\
\text { Pabbad }\end{array}$ & $\begin{array}{l}\text { Paabid` } \\
\text { seeba? } \\
\text { Paabid` }\end{array}$ & $\begin{array}{l}\text { Paabbe } \\
\text { seebbe } \\
\text { Peebbe }\end{array}$ \\
\hline
\end{tabular}

We extracted comparable targets with nasals, liquids and stops from the unplanned interactions. As we expected, the frequency of occurrence of each syllable type and consonant was variable. The pattern with the highest frequency was medial V1CCV2I structure and the consonants with the highest frequency were laterals and nasals. We noticed only two incidences of disyllables with the medial VV1CCV2 pattern which occurred in an unplanned speech corpus. A total of 200 spontaneous speech tokens and 440 word-list were analyzed.

As the recordings have been done into two stages/periods, the means of word delivery is different in each of these stages. In the first stage, the native speaker has uttered these words while the subjects are sitting face-to-face with the deliverer. This stage, which has been done in two locations in Jordan, has involved twenty-seven subjects judging the delivered words. In the second stage, the deliverer's utterances have been recorded, and three subjects have listened to his utterances. The reason for carrying out the methodology this way is that we have not managed to get thirty speakers in the face-to-face interaction. Also, having carried it out this way has given us the opportunity to involve more speakers of the Levantine Arabic variety-Syrian and Palestinian Arabic speakers-in this stage.

As the notion of inseparability (vowel insertion) has been the focus of this stage, the vowel epenthesis has not been done randomly, but it is based on the Arabic phonology rules, as well as Arabic phonology-morphology interaction rules. More specifically, it has targeted how Arabic forms the plural noun from its singular one when the singular has a geminate sound in it and vice versa. Also, it has targeted how Arabic inflects and conjugates its past verb to refer to the third-person singular masculine when the verb root has a geminate sound in it. As mentioned earlier, we have avoided including any nasal geminate in this stage as our hypotheses regarding Arabic nasal geminates go beyond the scope of the notion of inseparability. 
TABLE IV.

ARABIC WORDS WITH GEMINATES UNDERGOING EPENTHESIS

\begin{tabular}{|c|c|}
\hline Word & Word with Epenthesis \\
\hline /sadda/ & /sadada/ \\
\hline /hattaa/ & /hatataa/* \\
\hline /fiatta/ & /hatata/ \\
\hline /kattama/ & /katatama/* \\
\hline //djadda & /dzadada/? \\
\hline /dgaddii/ & /dguduudi/ \\
\hline /dyadd/ & /dzuduud/ \\
\hline /dgaddal/ & /dgadadal/* \\
\hline /xaddii/ & /xududii/ \\
\hline$/$ xadd/ & /xuduud/ \\
\hline /madda/ & /madada/ \\
\hline /maddan/ & $/$ madadan/* \\
\hline /habba/ & /hababa/ \\
\hline /habbah/ & /hababah/* \\
\hline /habbaka/ & /hababaka/* \\
\hline /mutti/ & /mutiti/? \\
\hline /sitti/ & /sititi/* \\
\hline /mattana/ & /matatana/* \\
\hline$/ \mathbf{x a t}^{\mathrm{s}} \mathbf{t}_{\mathrm{s}}^{\mathrm{a} /}$ & /xat'at'a/ \\
\hline$/$ xit $^{\mathrm{s}} \mathbf{t}^{\mathrm{s}} \mathbf{a h} /$ & $/$ xut'at $^{\natural} /$ \\
\hline$/ \mathbf{x a t}^{\mathrm{s}} \mathbf{t}^{\mathrm{S}} \mathbf{a t}^{\mathrm{s}} \mathbf{a} /$ & $/$ xat $^{\complement} a t^{\complement} a t^{\complement} a / *$ \\
\hline /bat't'ah/ & $/$ bat $^{\varsigma} a t^{\varsigma} a \mathrm{ah} / * /$ bat $^{\varsigma} a t^{\varsigma} / *$ \\
\hline /qit't'sh/ & /qit`at'ah//qit`at $/ /$ \\
\hline /ruzzah/ & /ruzaz/* \\
\hline /muzzah/ & /muzaz/ \\
\hline \multicolumn{2}{|c|}{$\begin{array}{l}\text { The asterisk (*) indicates that the word is unacceptable. } \\
\text { - The question mark (?) indicates that word is a position of debate; some subjects agree that it makes sense while others } \\
\text { contend that it does not, or it is not part of their lexicon. }\end{array}$} \\
\hline
\end{tabular}

We have controlled the independent variables here, which are gemination and epenthesis in relation to the dependent variables, which are the intelligibility of the sound and/or word in question and the underlying identity of the geminate sound: true or false. Based on Arabic native speakers' judgment of the different phonological and morphological environments in which these two types of geminate sounds occur, we have made some predictions regarding our hypotheses above, and we have reached the following results:

\section{Results}

Based on Arabic speakers' judgments of the intelligibility of the words in the table above, it seems that there are two kinds of long consonants in Arabic. These two sounds, which some scholars call geminates (Catford, 1977; Mitchell, 1990; Al Tamimi, 2004; Blanc, 1952; Kenstowicz and Pyle, 1973; to name a few), seem to behave differently, therefore,

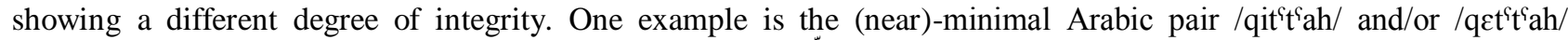

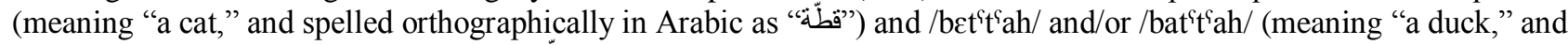
spelled orthographically in Arabic as "بطّ" "بط"). All subjects have spelled these two words in Phase 1 with the Arabic gemination diacritic (Ash-shaddah, ) over the geminate sounds. When vowel insertion has taken place in these two lexical words to form the plural form, following the Arabic morphological scale, speakers have judged and indicated

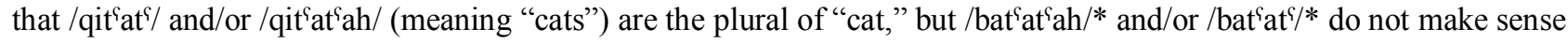

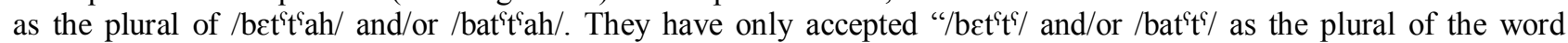
/bet $t^{\dagger} t^{\uparrow}$ ah/ and/or /bat' $t^{\top}$ ah/ (meaning, "a duck").

Another example is the minimal Arabic pair /muzzah/ (which is a slang word meaning "beautiful/attractive girl" and/or "chick," and spelled orthographically in Arabic as “"ز") and /ruzzah/ (meaning "one piece of rice," and spelled orthographically in Arabic as " " diacritic (Ash-shaddah) over the geminate sounds. When vowel insertion has taken place in these two lexical words to form the plural form, following the Arabic morphological scale, speakers have judged that /muzaz/ (meaning "beautiful girls/chicks") is the plural of "muzzah," but/ruzaz/*does not make sense as the plural of /ruzzah/. They have only accepted "/ruzz/" as the plural of the word /ruzzah/ (meaning "one piece of rice"). This particular example gives as a clear indication that true Arabic geminates, unlike fake ones, are likely to violate the Arabic morphological scale to maintain their internal bonds/ties within the long segment.

Arabic almost depends on the tri-consonantal root of the word to conjugate and form different parts of speech and different conjugations of the same root. Tri-consonantal root is a root that contains a sequence of three consonants. It seems that the geminate sound in the word "ruzzah" has violated the rules of the Arabic morphology scale in forming the plural from the singular-although /ruzzah/ has the same morphological scale and/or syllabic structure as /muzzah/. Based on Arabic morphology, the tri-consonantal root of the word /muzzah/ is $/ \mathrm{m}, \mathrm{z}$ and $\mathrm{z}$, which is by analogy taken from the tri-consonantal morphological root /f, S, and 1/- the form that Arabic speakers are taught in school to depend on when adopting conjugations. The point to be asserted here is that based on the Arabic morphology, a singular form 
that corresponds to /fuSlah/ should be pluralized as /fuSal/ and vice versa just like /Pummah/ (meaning "nation") and its plural form /Pumam/ (meaning "nations"), / yummah/ (meaning "difficulty/unpleasant situation") and its plural form /yumam/, and - as in our example_-/muzzah/ and its plural form /muzaz/. This leads us to conclude that /ruzzah/ should be pluralized as /ruzaz/ to comply with the Arabic morphological scale of words of such analogy. However, the word /ruzzah/ has one and only one plural form in Arabic, which is /ruzz/. The geminate sound here has not submitted to the notion of epenthesis as its sister in /muzzah/, an issue that brings the notion that these two sounds have different degrees of integrity on the gemination scale. While the /zz/ in /muzzah/ is a fake one, the /zz/ in /ruzzah/ is a true one.

Another example that supports the hypothesis that Levantine Arabic geminates may actually belong to two classes that behave differently from each other comes from this set of words in Table 5 below.

TABLE V

ARABIC INTERVOCALIC GEMINATE /TT/ UNDERGOING EPENTHESIS

\begin{tabular}{|l|l|}
\hline /hattaa/ & /hatataa/* \\
\hline /hatta/ & /hatata/ \\
\hline /kattama/ & /katatama/* \\
\hline - The asterisk $(*)$ indicates that the word is unacceptable. \\
\hline
\end{tabular}

Unlike our previous examples discussed above, which have been dealing with nouns, this set of words deals with verbs and functional words while the phonological position of the geminate is controlled. The Arabic word /hattaa/ is a functional word with two meanings and functions. It could be a preposition meaning "until," preceding Arabic nouns, but it could also precede verbs. In the latter, it then becomes an accusative function word. The word /hatta/ is the Arabic word for (it) "eroded," and the word /kattama/ means (he) "tried to obfuscate things securely and purposefully." As we can see, the geminates in all these words are intervocalic. However, when we have attempted to epenthesize the Arabic diacritic al-fatha, which is the accusative marker in Arabic and which is described as a small diacritic over the sound as in ( ), subjects have indicated that / hatta/ is the same as / hatata/ (meaning (it) "eroded"), but / hatataa/ does not mean / hattaa/ (meaning "until"). They have also indicated that / hatataa/ could be perceived as (it/he) "eroded" although it sounds odd and foreign to a certain extent. Some people might contend that we are looking at classes of words here of different nature, i.e., verbs vs. function words. To respond to this argument, we have attempted to epenthesize the geminate in /kattama/ (meaning (he) "tried to obfuscate things securely and purposefully") to produce /katatama/ in parallel with / hatta/ (meaning (it/he) "eroded"). This way, we have controlled the same part of speech and the same phonological environment of the Arabic geminate sound. Subjects have rejected /katatama/ as an Arabic word; they have indicated that it makes no sense. This is actually indicated with an asterisk in Table 4 and table 5 above. The results discussed here are not exhaustive of all the words included in Table 4. For more examples on this phonological discrepancy of Arabic geminates, more examples can be found in Table 4 above.

To test our third hypothesis above, we have attempted to measure the intelligibility of the words examined here using a t-test as follows: we have compared the underlying form of the word with the surface form-assuming that the latter is the one that has undergone epenthesis - in those words we think have fake geminates and those words we think have true geminates. For example, we have compared the intelligibility of the word /muzzah/ with the its plural form /muzzaz/, which both have been accepted as lexical words in Arabic and whose geminates are thought to be fake ones under the notion of inseparability. We have designated a hypothetical intelligibility scale of 0-4. Every word in the underlying form has scored 4 on the intelligibility scale. When epenthesis occurs, if the word still makes sense, it has scored 4 on the same scale; if epenthesis has resulted in rejecting the word, the surface form has scored 0 on the same intelligibility scale. We have also controlled this systematicity regarding the underlying and the surface forms in the case of true geminates. For example, we have compared the intelligibility of the word /ruzzah/ with the its supposed-tobe plural form /ruzaz/*_w while the former has been accepted as a lexical word in Arabic, the latter has not —whose geminate is thought to be a true one under the notion of inseparability. In parallel with the scale that we have adopted with fake geminates, we have designated a hypothetical scale of 0-4. Every word in the underlying form has scored 4 on the intelligibility scale. When epenthesis occurs, if the word still makes sense, it has scored 4 on the same scale; if epenthesis has resulted in rejecting the word by the subjects, the surface form has scored 0 on the intelligibility scale. Then, we have compared the means of the scores of the surface form in the case of fake geminates with the means of the scores of the surface form in the case of true geminates using the t-test and p-value.

Upon calculating and taking into consideration the means of the measurements in each category above and comparing it to the means of the measurements of the counterpart category and upon running a t-test to test our intelligibility hypothesis above, as well as the null hypothesis, which assumes that there is no difference in the intelligibility between fake epenthesized geminates and its true counterparts, we have obtained the results stated below. In our approach here, we have performed the t-test using paired data. We have also adopted the two-tailed test to see if the means could differ in both directions. In addition to that, we have also assumed that the variances are equal.

While the means of the intelligibility score of fake epenthesized geminates is 3.3 out of 4 , the means of the intelligibility score of true epenthesized geminates is 0 out of $4,(\mathrm{P}<.001)$. This means that the difference is extremely significant. At the same time, while the standard deviation of the intelligibility score of fake epenthesized geminates is 1.52, the standard deviation of the intelligibility score of true epenthesized geminates is 0 . The results of the $t$-test here support the intelligibility hypothesis here regarding the difference between true and fake geminates in Levantine Arabic. 
According to results obtained, the difference is very significant as it is extremely smaller than Alpha. This intelligibility relationship between fake epenthesized Arabic geminates and their true counterparts is plotted in Figure 1 below:

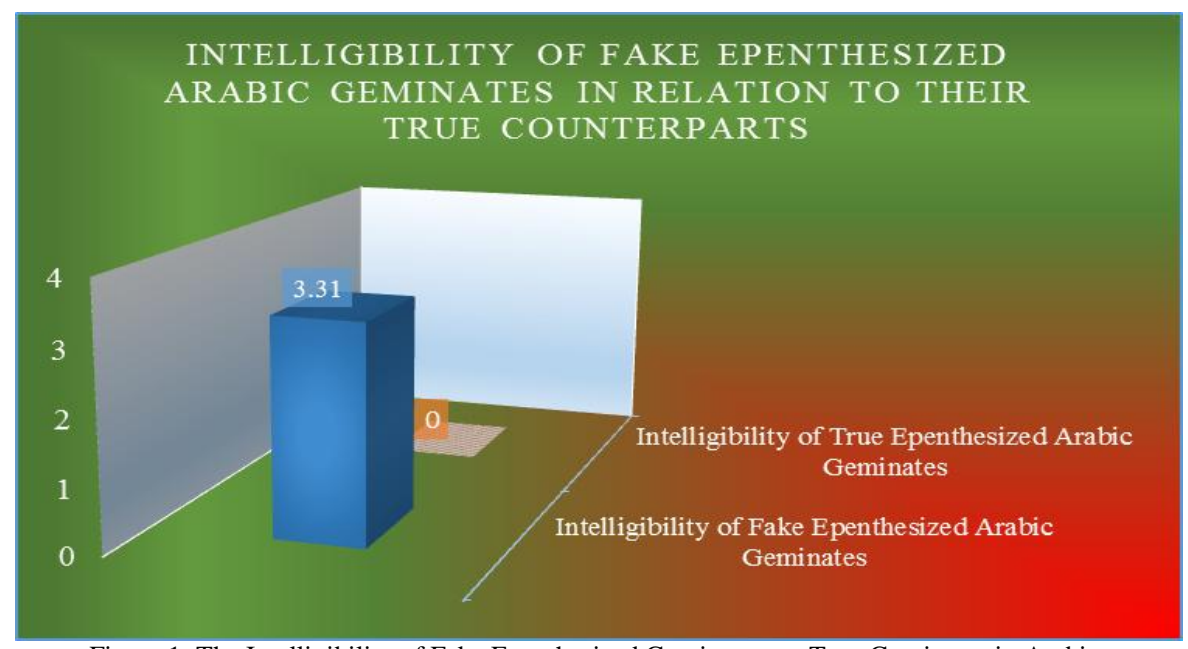

Figure 1. The Intelligibility of Fake Epenthesized Geminates vs. True Geminates in Arabic.

\section{DiSCUSSION AND CONCLUSION}

This stage of this case study has attempted to examine how Arabic geminates seem to behave differently. The data collected here tend to pose a very challenging issue regarding the interaction between phonetics, more specifically auditory phonetics, and CV phonology. Based on the notion of inseparability (vowel epenthesis), it seems to be the case that while Arabic speakers tend to auditorily and orthographically perceive two types of geminate sounds the same, when the CV phonology of Arabic interacts with its Arabic morphology sister, clues are given to native speakers to help them see through the true identity of the geminate sound in question.

Both nouns and verbs seem to be vulnerable to both kinds of geminates. For example - as we have seen - while the geminate sound /zz/ in the word /muzzah/ (meaning "beautiful girl") has submitted to vowel epenthesis to derive the plural one (/muzzaz/), the geminate sound /zz/ in the word /ruzzah/ (meaning "one piece of rice") has resisted vowel epenthesis to manufacture a plural form like /ruzaz/*. Instead, it has maintained its integrity manufacturing the plural form /ruzz/. Both of these words belong to the same part of speech, i.e. nouns. However, the geminate sound in the latter has maintained its true identity and resisted epenthesis.

In fact, another intriguing example has come from Al-Qamuus Al-Muhit ${ }^{\varsigma}$ by Fairuzabadi (1887), an authority dictionary in Arabic in general and Levantine Standard Arabic in particular. Two intriguing words are listed in the dictionary. Examining these words and how the plural forms are created makes compelling evidence that Arabic

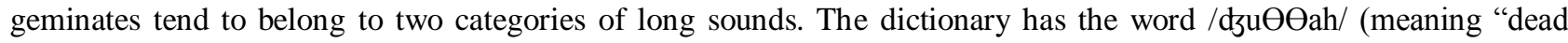
body") and the word /GuӨӨah/ (meaning "moth") (Brame, 1970). These two words seem to challenge the way the literature has defined geminates. Much of the research that has been done in this regard brings to light that geminates require exaggerated muscular tension done by the active articulators involved in their articulation. In this regard, the articulators are held in a position accompanied by maintaining a longer blockage (occlusion) period for the geminate contoid production (Catford 1977, p. 298). It seems that the literature has been dealing with geminates as stop sounds; however, the pair of words listed above deals with fricative geminates. The argument to be made above is that while AlFairozabadi-who compiled the dictionary based on older Arabic dictionaries and based on how early Arabs had

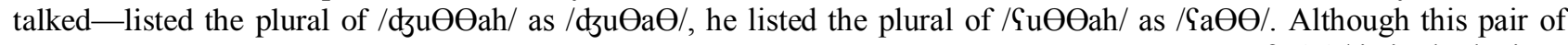
words was not within the set of words listed in Table 1 , when asked, subjects have agreed that $/ \mathrm{ha} \Theta \Theta /$ is in the lexicon

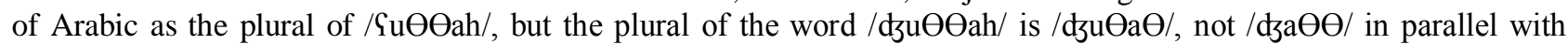
$/ \mathrm{Sa \Theta \Theta} /$.

Not only are Arabic nouns vulnerable to both types of geminates (true and fake), but so are Arabic verbs (Kenstowicz, 1994). An example discussed earlier is the verb / hatta/ that has gone vowel epenthesis resulting in /hatata/ (meaning (it) "eroded"). However, the geminate sound in the verb /kattama/ (meaning (he) "obfuscated things on purpose") does not accept epenthesis, resulting in a non-sense Arabic word.

Another example that should be examined is the Jordanian and Palestinian Arabic epenthesis in /mutt/ (meaning "I passed away") and its variant /mutit/, which has maintained the lexical meaning of /mutt/. In contrast with that, it does not seem that this epenthesis works with /sitt/ (meaning "a lady's title" and/or "grandmother"). When /sitt/ undergoes this sort of epenthesis, the outcome is a non-sense word (sitit*). These findings also reinforce Abu-Salim's (1980). He contends that in Palestinian Arabic /fut-t/ (meaning "I entered") is vulnerable to epenthesis, resulting in /futit/, which still carries the meaning of /fut-t/, but /sitt/ seems to resist this epenthesis, /sistit/*. If we are to take /mutt/ and /futt/ as the underlying monomorphemic forms, and if we are to take Arabic singular nouns as the underlying forms of the plural 
ones, the findings here seem to contradict what some of the literature has claimed particularly about true geminates; geminates are assumed to be true in monomorphemic words (McCarthy, 1986).

This leads us to conclude that it seems that these sounds have different representation on the phonological CV tiers. According to Broselow (1992), while fake geminates should be interpreted as a re-articulation of the consonant itself, true geminates should be viewed as one and only one sound that maintains its singularity over two timing slots. The following diagrams explain this discrepancy:

a) The phonological tier representation of the fake Arabic geminate in the word /muzzah/:

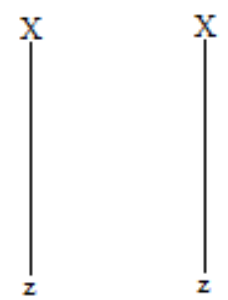

b) The phonological tier representation of the true Arabic geminate in the word /ruzzah/:

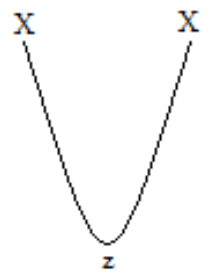

By adopting these phonological tier representations of Arabic geminates, we believe we can bridge the gap between those contentious views of geminate representation in the field. The above geminate representations tend to compromise the different points of views of representing geminates. While the first representation here indicates that geminates of similar nature are fake ones, the second representation indicates that geminates of similar nature are true ones. This representation or distinction between these categories of geminates does not also seem to contradict the Obligatory Contour Principle in the following perspectives. It seems that the plural noun in Arabic is the underlying form of the singular one. For example, /muzaz/ is the underlying form of /muzzah/ and /ruzz/ is the underlying form of /ruzzah/. The Obligatory Contour Principles tends to claim that sequences of identical segments should be precluded. If we encounter a cluster of such segments, it is because the underlying form of such segments has a segment that once has broken this cluster, yet this segment has been deleted in the surface form. If we examine the examples of Arabic nouns we have investigated thus far, we could assume that the singular form has come from the plural one, which had a vowel that once broke this cluster that appears in the surface form, the singular noun.

On the other hand, since the Obligatory Contour Principle is relevant to singly-linked adjacent segments, this does not contradict the behavior of true geminates, which are multiply-linked segments as the OCP tends not to question that. This also leads us to contend that fake geminates accept epenthesis because they do not have the capacity to have internal ties that correspond to a single multiply-linked line. At the same time, those geminates that do not accept epenthesis have the capacity to have internal ties that correspond to a single multiply-linked line. These findings also seem to explain the constraint on crossing association lines. That is, while fake geminates accept epenthesis, true ones do not due the ban that results from crossing association lines. The following diagrams explain this:

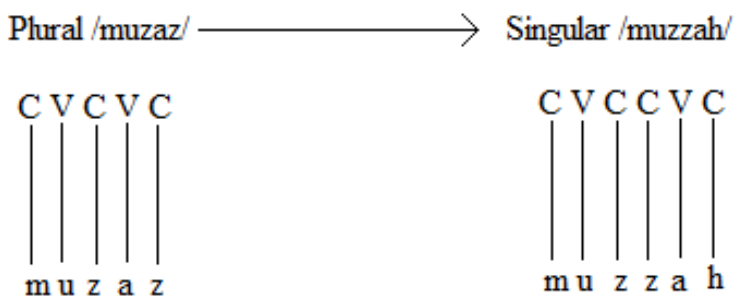

The CV tier representation of the fake geminate in the Arabic word /muzzah/ and its plural form /muzaz/ 


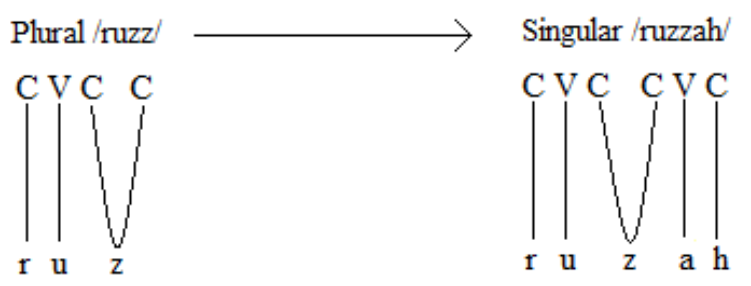

The CV tier representation of the true geminate in the Arabic word /ruzzah/ and its plural form /ruzz/

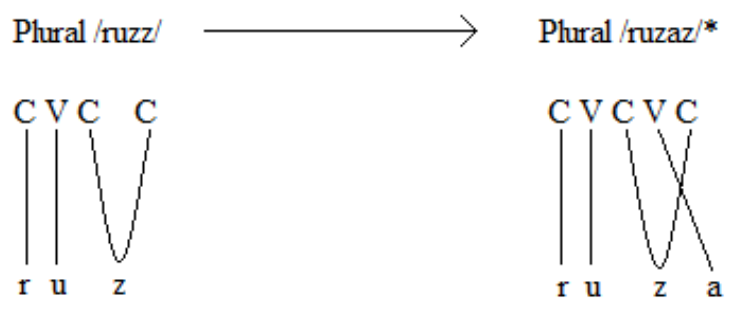

The CV tier representation of the true geminate in the non-sense plural Arabic noun /ruzaz/ and its plural form /ruzz/

*The asterisk indicates that the word does not exist in the Arabic lexicon due to the violation of the constraint on crossing lines.

Based on these different representations and in the light of the Obligatory Contour Principle, we could assume that fake Levantine Arabic geminates tend to be represented as a cluster of [-long] [-long] while their true counterparts tend to be represented as a unit of sound that has the feature [+long]. The following CV representations show this discrepancy:

Levantine Arabic Singular/muzzah/

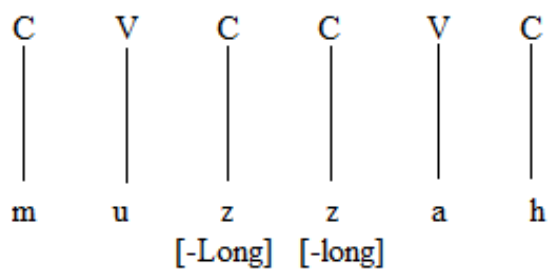

Levantine Arabic Singular /ruzzah/

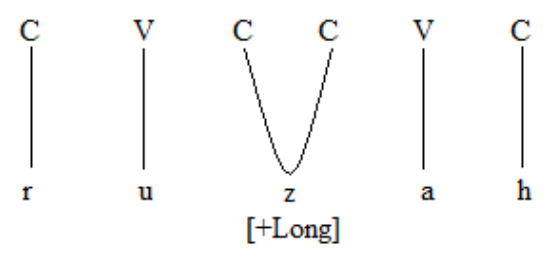

\section{REFERENCES}

[1] Abu-Abbas, K. H., Zuraiq W. M., \& Abdel-Ghafer, O. A. (2011). Geminates and long consonants in Jordanian Arabic. International Journal of Linguistics, 3(1), 1-17.

[2] Abu-Salim, I. M. \& H. R. Abd-El-Jawad. (1988). Syllable patterns in Levantine Arabic. Studies in the Linguistic Sciences, 18(2), 1-22.

[3] Al-Tamimi, F., Abu-Abbas, K., \& Tarawneh, R. (2010). Jordanian Arabic final geminates: An experimental clinical phonetic study. Poznań Studies in Contemporary Linguistics, 46 (2), 111-125.

[4] Al-Tamimi, F. (2004). An experimental phonetic study of intervocalic singleton and geminate sonorants in Jordanian Arabic. Al-Arabiyya, 29, 37-52.

[5] Arvaniti, A. \& Tserdanelis G. (2000). On the phonetics of geminates: Evidence from Cypriot Greek. Spoken Language Processing. Paper presented at the $6^{\text {th }}$ International Conference on Spoken Language Processing, Beijing, China (559-562). Beijing, China. Ohio: Ohio State University.

[6] Ball, M. \& Rahilly, J. (1999). Phonetics: The science of speech. London: Arnold.

[7] Blanc, H. (1952). Studies in north Palestinian Arabic. Jerusalem: Central Press.

[8] Brame, M. (1970). Arabic phonology: Implications for phonological theory and historical Semitic (Doctoral dissertation). Retrieved from http://www.ai.mit.edu/projects/dm/theses/ Retrieved on 12/5/2018. 
[9] Broselow, E. (1992). Parametric variation in Arabic dialect phonology. In E. Broselow, M. Eid \& J. McCarthy (Eds.), Perspectives on Arabic linguistics, 7-46). Amsterdam: John Benjamins.

[10] Catford, J. (1977). Fundamental problems in phonetics. Edinburgh: Edinburgh university press.

[11] Crystal, D. (2011). A Dictionary of Linguistics and Phonetics. Hoboken, NJ: John Wiley \& Sons.

[12] Davis, Stuart. (2011). 'Geminates'. In the Blackwell Companion to Phonology, Marc van Oostendorp, Colin J. Ewen, Elizabeth Hume and Keren Rice (eds). Chapter 37, pp. 873-897. Wiley.

[13] Delattre, P. (1971). Pharyngeal features in the consonants of Arabic, German, Spanish, French, and American English. Phonetica, 23, 129-55.

[14] Garcia-Sierra, A., Diehl, R. L., \& Champlin, C. (2009). Testing the double phonemic boundary in bilinguals. Speech Communication, 51(4), 369-378. doi:10.1016/j.specom.2008.11.005

[15] Ghalib, M. (1984). An experimental study of consonant gemination in Iraqi colloquial Arabic (Unpublished doctoral dissertation). United Kingdom: The University of Leeds.

[16] Ham, W. H. (1998). Phonetic and phonological aspects of geminate timing (Bernese, Hungarian, Levantine Arabic, Madurese) (PhD dissertation). Cornell University, Ithaca, NY.

[17] Ladefoged, P., \& Maddieson, I. (1996). The sounds of the world's languages. Oxford: Blackwell Publishers.

[18] Lahiri, A., \& Hankamer, J. (1988). The timing of geminate consonants. Journal of Phonetics, 16(3), 327-338.

[19] Kenstowicz, M. (1994). Phonology in generative grammar. Oxford: Blackwell Publishers.

[20] Kenstowicz, M. J., \& Pyle, C. W. (1973). Issues in Phonological Theory: Proceedings of the Urbana Conference on Phonology, 1971, University of Illinois. Berlin, Germany: Walter de Gruyter.

[21] Kiefer, F., \& Sterkenburg, P. V. (2012). Eight Decades of General Linguistics: The History of CIPL and Its Role in the History of Linguistics. Leiden, Netherlands: BRILL.

[22] Ladefoged, P. \& Maddieson, I. (1996). The sounds of the world's languages. Oxford: Blackwell's.

[23] Mahendra, L., Govindarajan, S., Jayanandan, M., Shamsudeen, S. M., Kumar, N., \& Madasamy, R. (2014). Complete Bilateral Gemination of Maxillary Incisors with Separate Root Canals. Case Reports in Dentistry, 2014, 1-4. doi:10.1155/2014/425343.

[24] McCarthy, J. (1986). The representation of consonant length in Hebrew. Linguistic Inquiry, 12, 322-327.

[25] Mitchell, T. (1990). Pronouncing Arabic 2. Oxford: Clarendon Press.

[26] Obrecht, D. H. (1965). Three experiments in the perception of geminate consonants in Arabic. Language and Speech, 8, 31-41.

[27] Oh, G. E., \& Redford, M. A. (2012). The production and phonetic representation of fake geminates in English. Journal of Phonetics, 40, 82-91.

[28] Ridouane, R. (2010). Geminates at the junction of phonetics and phonology. Phonology and Phonetics [PP]. doi:10.1515/9783110224917.1.61.

[29] Thurgood, G. (1993). Geminates: A cross-linguistic examination. In N. Joe, M. Gerald \& T. Graham (Eds.). Papers in Honor of Frederick Brengelman on the occasion of the twenty-fifth anniversary of the Department of Linguistics (pp. 129-139). Fresno: California State University.

Ahmad Mahmoud Saidat is an associate professor of linguistics in the department of English language and literature at AlHussein bin Talal University. He graduated from the University of Texas at Arlington in 2006. His research interests include syntax, morphology, morphophonemics, language attitude and change, and sociolinguistics.

Jamal A. Khlifat is a researcher at the University of Colorado, Boulder, United States. His research interests include forensic linguistics, phonetics, phonology (pharyngealization and pharyngeal harmony in Levantine Arabic, gemination in Levantine Arabic, nasalization and nasal geminates in Levantine Arabic, and prosody), syntax, lexical semantics, documentation of the world's endangered languages, and rhetoric and Toulmin-style argumentation. 